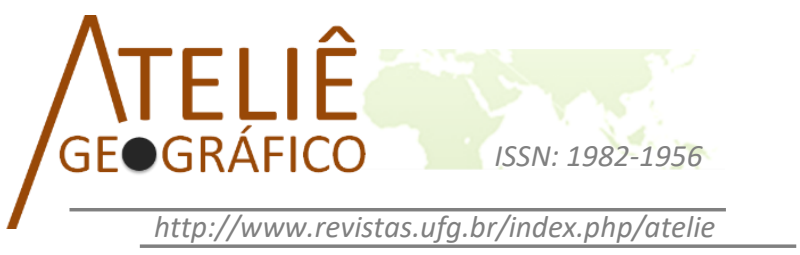

\section{Corporação, espaço e organização reticular: notas conceituais}

\author{
Corporation, space and reticular organization: conceptual notes
}

Corporation, espace et organisation réticulée: notes conceptuelles

\author{
Fernando Fernandes de Oliveira \\ Instituto Federal Goiano - Campus Avançado Ipameri \\ fernando.oliveira@ifgoiano.edu.br
}

\section{Resumo}

As corporações exercem evidente papel ante a estruturação espacial no capitalismo. Tal racionalidade perpassa pela incessante busca por difusão das condições produtivas indispensáveis à reprodução dos capitais numa escala ampliada de ação. $\mathrm{O}$ presente ensaio busca resgatar criticamente uma abordagem de estudos econômicos e geográficos que tiveram importância no entendimento da relação entre corporação, espaço, organização em rede e dos laços político-econômicos atados junto ao aparato institucional do Estado. Mira, nessa condição, dar continuidade aos amparos teóricos que visam conferir inteligibilidade para as tramas espaciais da grande corporação, assim compreendida como objeto de apreciação da Geografia.

Palavras-chave: Corporação multilocalizada, estrutura organizacional, redes, Estado.

\begin{abstract}
The corporations exert an apparent role regarding the spatial organization of capitalism. Such rationality passes through the unceasing search for diffusion of the productive conditions indispensable to the reproduction of capital in an extended action scale. The present paper seeks to redeem critically an approach of economic and geographic studies which had importance in the understanding of the relation among corporation, space, network organization and political-economic ties bound along with the State institutional apparatus. Aiming, in this condition, to give continuity to the theoretical support which aims at granting intelligibility for spatial plots of the great corporation, thus understood as Geography's subject of appreciation.
\end{abstract}

Keywords: Multi-local corporation, organizational structure, networks, State. 


\begin{abstract}
Résumé
Les corporations exercent un rôle évident devant la structuration spatiale au capitalisme. Telle rationalité traverse l'incessante recherche de diffusion des conditions productives indispensables à la reproduction du capital dans une échelle agrandie d'action. Le présent essai a comme objectif récupérer, de façon critique, une approche d'études économiques et géographiques qui ont joué un rôle important dans l'entendement de la relation entre la corporation, l'espace, l'organisation en réseau et les liens politico-économiques attachés à l'appareil institutionnel d'État. Il vise, sous cette condition, poursuivre les supports théoriques qui confèrent l'intelligibilité aux relations spatiales de la grande corporation, ainsi comprise comme objet d'appréciation de la Géographie.
\end{abstract}

Mots clé: Corporation multi localisée, structure organisationnelle, réseaux, État.

\title{
Introdução
}

As origens da complexa trama espacial das corporações multilocalizadas decorrem da racionalidade que busca a integração de suas difusas unidades e pelo profícuo esforço que tenciona alcançar a máxima vantagem sobre as estruturas técnicas disponíveis. O desempenho econômico e as solicitações privatícias da grande corporação resultam em notória influência nos processos de reorganização do espaço geográfico. As suas práticas de gestão colaboram por alterar a ordem espacial preexistente.

O escopo do presente texto é o de analisar a evolução da investigação geográfica acerca do movimento de difusão espacial das corporações, que ordenam múltiplas localizações e frentes de atuação. Para tanto, a primeira parte expõe, num quadro de ruptura conceitual, os limites das abordagens atinentes aos fatores locacionais da firma neoclássica mediante as transformações do próprio objeto, contexto de emergência da corporação multidivisional. Tais mudanças organizacionais são abordadas em paralelo à expansão geográfica da acumulação capitalista, pontuada na segunda parte. Por fim, busca-se a inter-relação de recortes espaciais críveis à análise das trajetórias espaciais de corporações multilocalizadas, assim como as relações sinérgicas mantidas com o aparato estatal para a produção de um espaço reticular que atenda às solicitações desses atores.

\section{Os limites da abordagem neoclássica mediante a emergência da corporação multidivisional}

Na gênese dos estudos referentes à dinâmica espacial das empresas como objeto de exame, destacam-se as abordagens neoclássicas oriundas do período que se estende do fim do século XIX à primeira metade do século XX. Via de regra, essas análises se restringiam à iniciativa individual do empreendedor as práticas de localização, ao considerar o perfil das firmas daquele período, iminentemente unidimencionais e 
monoprodutivas. Com efeito, os postulados iniciais estiveram sedimentados na minimização dos custos relativos ao transporte, de Alfred Weber (1909); na maximização dos lucros por meio da análise de áreas de alcance de mercado, de August Lösch (1940), ambos pertencentes à escola alemã de localização industrial; e na apropriação de vantagens locacionais oportunizadas pelos fatores aglomerativos, de Alfred Marshall (1920; 1996), figura central da corrente neoclássica sediada na Inglaterra.

Grosso modo, as mencionadas abordagens estiveram na base dos primeiros esforços que buscaram a compreensão das questões pertinentes às implicações espaciais das firmas industriais, cujos amparos metodológicos partem de pressupostos perfeitamente delineados do que pertence à concorrência e ao acesso à informação. Sem negligenciar a importância da herança neoclássica atinente às relações entre indústria e espaço, é possível reconhecer que essas leituras estiveram sedimentadas em hipóteses restritivas, cuja iniciativa isolada do empreendedor representa o cerne das estratégias de localização de firmas monoproduto e de breve alcance espacial.

No que diz respeito à dinâmica espacial do universo neoclássico, Claval (2012) pontua que o espaço é compreendido como obstáculo aos meios de transporte, na medida em que os efeitos da distância emergem como fator explicativo para a localização das atividades econômicas, numa leitura demasiadamente centrada na escolha acerca da melhor localização para determinada atividade e da melhor atividade para um dado local, como salienta Pires do Rio (1998). Tais relações ocorriam sobre um espaço-plataforma dado, inerte e receptor de decisões individuais, marcado por apatia e estabilidade estanques, de modo que "as relações espaciais e as configurações geográficas se produzem passam, na maioria dos casos, desapercebidas ou ignoradas" (HARVEY, 2005, p. 140).

Não obstante à crescente complexidade das operações intraempresa e no consequente impacto à sua dimensão espacial, a firma é vista como uma extensão da própria família, na medida em que essas duas unidades procuram a maximização dos seus respectivos orçamentos, de forma que a soma dos gastos seja a menor possível se comparada aos rendimentos totais. $\mathrm{Na}$ aurora do século $\mathrm{XX}$, o contexto das transformações imanentes à própria natureza das relações capitalistas demandara a expansão de um novo padrão técnico responsável por proporcionar notável alargamento das escalas de atuação das corporações, cujo escopo não prescindiu a uma verdadeira revolução organizacional dos fazeres institucionais, em detrimento do tradicional arranjo familiar neoclássico.

O objeto cresce em complexidade, vista a ampliação dos seus espaços de intervenção e da crescente segmentação operacional. Significa, segundo Fischer (2008), a emergência de um novo modo de estruturação de empresas que se organizam de forma reticular, dotadas de maior competência no que concerne à mobilidade espacial. A instantaneidade e a simultaneidade alcançadas na atualidade são resultado, como nos lembra Corrêa (1997), das demandas de interação daquelas corporações multilocalizadas 
que ordenam variada gama de funções, produtos e inúmeras localizações, acenando para o peso desses atores ${ }^{1}$ no que diz respeito à organização do espaço econômico. Este, como registra Pires do Rio (2012), passou a ser visto como resultante das ações, das práticas e das estratégias dos atores, e não mais como estrutura exógena definida pela mera distância geométrica, tal como nos pressupostos apriorísticos da interpretação neoclássica.

No âmbito das transformações teórico-metodológicas que propuseram a renovação das abordagens sobre uma teoria das empresas, destacam-se as contribuições de Ronald Coase (1937), Edith Penrose (1959), e Alfred Chandler (1962; 1977), cujo escopo mantém-se alinhado aos processos decisórios internos que, indubitavelmente, possuem implicações determinantes para a ordem espacial das corporações. Tratou-se dos esforços de revisão conceitual perante o crescente perfil multidivisional mediante a constante expansão das escalas espaciais de intervenção das grandes corporações, de modo que as práticas de compra, venda, instalação de ativos fixos e estratégias de competição inserem-se num cenário geográfico, como nos lembra Markusen (2005).

Ao propor uma leitura do fenômeno empresarial para além das redondas estimativas de um mercado ideal e perfeitamente equilibrado, Ronald Coase, num ensaio publicado em 1937, atribuiu relevo àquilo que denominou de custos de transação. Tais custos fazem referência à amplitude dos fatores atinentes aos aspectos gerais das atividades econômicas e seus riscos inerentes, demonstrando as arestas de um mercado imperfeito e imbuído de incertezas, tais como variações inesperadas de preços, quebras contratuais, calotes, prazos não cumpridos, dentre outros percalços. A solução sugerida pelo mencionado autor para a diminuição dos infortúnios, próprios aos custos de transação, deriva de uma ferramenta organizacional baseada no princípio da internalização ${ }^{2}$, "de modo que vários contratos externos sejam substituídos por um" (COASE, 1937, p. 4).

Na batalha contra os mencionados custos, a corporação buscará, no contexto da ampliação de suas escalas funcionais e espaciais, a criação de um mercado interno próprio, valendo-se dos mecanismos de fusão e de aquisição que possibilitam o acúmulo de vantagens competitivas para a empresa multilocalizada, no que diz respeito ao ordenamento das atividades pulverizadas. Todavia, na avaliação de Chesnais (1996), a internalização passa de estratégia de proteção para prática que potencializa as

\footnotetext{
${ }^{1}$ Para a acepção da corporação como ator, seguimos a sugestão de Markusen (2005, p. 58), que define os atores como "instituições que funcionam como agentes decisórios, empreendedores que decidem estabelecer ou criar firmas em determinados locais e trabalhadores que tomam a decisão de migrar".

${ }^{2}$ Uma releitura dos custos de transação é proposta por Williamson (1973; 1981), para quem os mencionados custos constituem a soma aferida pela racionalidade limitada dos atores, pelo oportunismo e pelas incertezas e informações imperfeitas vindas do ambiente externo.
} 
imperfeições do mercado, visto que, uma vez ampliada a ponto de originar estruturas oligopolistas, acaba por promover o aprofundamento de tais imperfeições, agora em benefício dos grandes grupos empresariais, gerando consideráveis limites à concorrência.

Penrose (1959), por seu turno, vê a empresa como um conjunto fatores técnicos e humanos para a produção de bens e serviços, possuindo evidente capacidade para acumular e gerar competências e conhecimento. Rompendo com o caráter estático da firma neoclássica, a reunião de capacidades gestoras, técnicas e produtivas conferem à corporação um conteúdo dinâmico, adaptativo e inovador que, em última análise, representa as condições necessárias para o crescimento e diversificação funcional das unidades empresariais, com reflexos evidentes à sua trama espacial. Aprendizagem, administração e diversificação da produção via processos de fusão e aquisição emergem como estratégias de crescimento e expansão, na medida em que a construção do conhecimento cria "oportunidades produtivas que permitem à empresa não só "mudar de maneiras não relacionadas a mudanças no meio ambiente, mas também contribui para a 'singularidade' da oportunidade de cada empresa individual" (PENROSE, 2009, p. 47$48)$.

Em realidade, a consolidação dos processos de fusão e aquisição mantém relação direta com a ampliação das escalas espaciais do objeto em pauta, demandando a configuração de mecanismos de administração descentralizados que conformem um arranjo organizacional competente para as práticas de alocação dos capitais, difusão de novos produtos e prestação de serviços destinados ao alcance de mercados distantes. No tocante às transformações organizacionais como suporte para a expansão de grandes corporações, o proeminente trabalho de Chandler (1962) atribui notável relevo à espacialidade intrínseca aos mecanismos de uma administração descentralizada e interligada por uma trama hierárquica de unidades e gestores.

Esse autor reconhece a complexidade administrativa de grandes corporações por meio de um padrão reticular que interliga múltiplos escritórios, cuja lógica espacial obedece ao contexto da divisão do trabalho interno à própria corporação, uma organização multidivisional estruturada em níveis hierárquicos que operam diferentes escalas espaciais e funcionais. Para a compreensão das estratégias de crescimento das empresas, Chandler (1962) abordou de forma pormenorizada a história de consolidação, expansão e evolução da estrutura organizacional das gigantes estadunidenses General Motors, Standard Oil of New Jersey, Sears \& Rouebuck e Du Pont. Segundo o autor, as mencionadas corporações foram as primeiras a promover uma série de reestruturações intraempresa que, propostas num curto período entre segunda metade da década de 1920 ao início dos anos 1930, buscaram a reordenação das estruturas administrativas que permitissem uma operacionalização multidivisional e descentralizada.

Provecto, o diagnóstico de Chandler (1962) confere à moderna corporação que ordena múltiplas funções e localizações, a configuração de um arranjo de unidades operacionais descentralizadas e amarradas por uma rede hierárquica de diretores 
executivos, gerentes e administradores com competências funcionais distintas, que variam do mais complexo ao mais banal dentro da estrutura interna da empresa. Trata-se do conjunto de mudanças verificadas na estrutura organizacional acabam por concretizar a evolução têmporo-espacial da atuação do objeto em pauta, indicando possibilidades à delimitação periodizada dos eventos que deflagraram as transformações em escala espacial e em estrutura funcional de uma grande empresa. As estratégias perfazem um acontecer hierárquico, condutor de ordens e informações (SANTOS, 2012); de modo que o ordenamento, não raras vezes distante, representa um dos elementos que permitem a Santos (2012, p. 139) afirmar que "cada lugar é teatro de tempos 'externos', múltiplos".

O histórico das transformações responsáveis pela emergência das grandes corporações não prescindiu, evidentemente, da implantação dos sistemas técnicoreticulares indispensáveis à difusão espacial do comércio e do consumo em massa nos Estados Unidos, palco das análises de Chandler (1962; 1977). Os ganhos em eficiência possibilitados pelas ferrovias, portos fluviais e marítimos e sistemas de telégrafos, uma vez associados ao desenvolvimento das estratégias de marketing, possibilitaram notória ampliação das escalas de atuação das firmas analisadas. Rompem-se, desta forma, "as amarras de horizontes espaciais limitados e fortemente fechados, submetidos a uma economia preponderantemente autárquica" (CORRÊA, 1997, p. 282), articulação sobremodo oportunizado pelo uso privilegiado das redes técnicas.

Em realidade, é fácil perceber que ao passo da concentração de capitais e de funções, sobremodo possibilitada pela internalização em escala e escopo, ocorre progressiva difusão espacial e descentralização administrativa, que mantém coesão sedimentada pela hierarquia gerencial e pela estrutura multidivisional, estratégias organizacionais ratificadas pelo advento das redes técnicas e geográficas ${ }^{3}$. Entretanto, no que pertence aos mecanismos de acumulação e centralização dos capitais, emergem notas para a espacialização multiescalar do capital e, necessariamente, da grande corporação que escapam às análises que buscam uma teoria da firma postas em revista até o momento.

\section{A corporação multidivisional sob a óptica da dimensão espacial da acumulação de capitais}

Os aspectos comportamentais e a aprendizagem, a geração de competências referentes às capacidades organizacionais internas e o contexto de emergência da corporação multidivisional mediante crescente internalização compõem a tônica central das indispensáveis contribuições formuladas por Coase (1937), Penrose (1959),

${ }^{3}$ Castilho (2016) entende as redes técnicas ou infraestruturais como aquelas que fornecem suporte a toda sorte de fluxos materiais ou imateriais, como as ferrovias, as rodovias e as redes de telecomunicações. Para Corrêa (2014, p. 107), as redes geográficas correspondem ao "conjunto de localizações geográficas interconectadas entre si, por um certo número de ligações”. 
Chandler $(1962 ; 1977)$. Tais abordagens possuem iminente correspondente espacial, ainda que a emergência das espacialidades do objeto de apreciação não seja a preocupação definitiva desses estudos. Vigorosas no que concerne à elucidação do arranjo organizacional interno, demonstram pendente fragilidade relativa à dimensão geográfica. Nesses termos, para melhor apreensão daquilo que é concreto e objetivo, busca-se, tal como sugere Harvey (2005), "friccionar" blocos conceituais, a fim de que sejam elencados enfoques tão preciosos quanto aqueles já mencionados.

À guisa de analogia, é interessante perceber a aproximação das perspectivas adotadas por Penrose e Chandler às considerações de Santos (2008), no que pertence ao reconhecimento das técnicas como elementos de explicação da sociedade, dos lugares e como recursos imprescindíveis ao funcionamento eficiente das empresas. Admite o autor, acenando para nuanças políticas, a importância do agir eficaz do que chamou de "formas organizativas" sobre o arranjo dos objetos como condição essencial para a rentabilidade das corporações, visto que a análise do conteúdo técnico do espaço, como recurso para as organizações, exige uma incursão profunda nas relações sociais. Disso resulta o poderio econômico da grande corporação, dado pela "maior ou menor capacidade de combinar eficazmente os fatores da produção de que dispõe do ponto de vista eminentemente técnico, o que concerne à produção imediata" (SANTOS, 2008, p. 59).

Remete às ações sedimentadas em iniciativas "que marcaram época, tomadas por empresas que causaram impactos extraordinários sobre a geografia econômica", como bem observa Markusen (2005, p. 64). A competência organizacional intrínseca ao eficaz manuseio dos objetos técnicos disponibilizados, que, no contexto da expansão dos mercados e da rentabilidade, faz resultar força econômica e também política. Se as técnicas, uma vez animadas pelas relações sociais são capazes de explicar as diferenças entre os lugares, assim como a sua crescente complementaridade, o uso eficaz dos objetos no contexto intraempresa pode ser visto como um indicador da força das corporações multilocalizadas em sua sincronia espacial.

O espaço, juntamente com a evolução de suas estruturas técnicas, torna-se palco, meio e condição para o estabelecimento das diversas práticas socioespaciais arquitetadas pela corporação multilocalizada, ações lastreadas por evidente associação dos poderes econômico e político. Daí a crescente demanda pelo investimento de ativos fixos no espaço, o conjunto de modernizações ${ }^{4}$ que exprime a concreta dinâmica socioespacial do capital produtivo. A dimensão espacial da corporação, antes condensada na busca pela localização ideal aferida em função dos recursos necessários e do mercado consumidor, encontra, na qualidade e na competência das estruturas espaciais em entregar de fluidez, a tônica para as decisões estratégicas de difusão.

${ }^{4}$ Castilho (2016) admite modernização como o conjunto das racionalidades hegemônicas que se inscrevem no espaço na forma de infraestruturas econômicas, envolvendo, ainda, aspectos políticos e ideológicos. 
Não obstante, as suas práticas de gestão territorial, quando plenamente capazes de integrar os mencionados ativos fixos, concorrem para reafirmar os atributos do espaço em escala e substância, como bem observa Silva (2003). Ávidos por expansão constante, os imperativos da acumulação demandam a criação de novos espaços dotados de infraestruturas, consubstanciando "tipos específicos de estruturas geográficas" segundo Harvey (2005, p. 41). A premissa, sedimentada na mobilização material e social em favor da acumulação, engendra processos em múltiplas escalas de ação, esforço que denota o firmamento de uma esfera unificada de reprodução e valorização de capitais.

A acumulação dos capitais, em sua concretude, "não é mais do que a reprodução do capital em escala progressiva” (MARX, 2013, p. 799). Para o seu pleno cumprimento, as relações capitalistas exoram o rearranjo de atividades preexistentes sob a égide do capital, instigando a criação de novos desejos e necessidades por meio de novas linhas de produtos, além de promover a necessária difusão geográfica para outras regiões do país ou para o exterior, dinâmica imprescindível ao êxito da acumulação.

$\mathrm{Na}$ narrativa proposta por Chandler (1962), histórico das transformações que demandaram a integração vertical, o padrão multidivisional e a consequente difusão espacial da grande empresa mantêm fundamento nas capacidades organizacionais voltadas para a satisfação das demandas do mercado ante concorrência e inovação. Nesse contexto, Chandler (1977) lança mão de sugestiva analogia no título de The Visible Hand, trabalho no qual sustenta que a "mão invisível", expressa no clássico de Adam Smith (1996), fora substituída pela estrutura organizacional da grande corporação, um modus operandi que tangencia o próprio sistema.

Todavia, o registro de Marx (2011), no que diz respeito à premissa da indução de novos desejos e necessidades, permite propor a leitura de que os caminhos que levam à multifuncionalidade e à multilocalização representam estratégias que desenham novas oportunidades para a acumulação adicional de capitais. Por conseguinte, Harvey (2005, p. 62), resgatando a dimensão espacial contida no âmbito das formulações marxianas, acrescenta que "a expansão é, simultaneamente, intensificação (dos desejos, das necessidades sociais, de populações totais, e assim por diante) e expansão geográfica", e não necessariamente em função dos auspícios da utilidade, da livre concorrência e do mercado autorregulável, como na ilustração sugerida por Chandler (1977).

Entrementes, na intenção de friccionar as mencionadas perspectivas, cumpre registrar que Harvey $(2005$; 2013) não negligencia o exame proposto por Chandler (1962; 1977); antes, resgata-o criticamente. Nessa condição, as transformações organizacionais podem ser identificadas sob uma óptica marxiana, visto que "a necessidade de realizar revoluções perpétuas nas forças produtivas implica, então, que devem existir revoluções perpétuas na organização da produção", como reforça Harvey (2013, p. 235).

Disso resulta o indesejável poder oligopolista das grandes corporações, cuja pujança permite a Harvey (2005, p. 222) concluir que "a mão visível da empresa, como Chandler a denomina, foi muito mais importante para a geografia histórica capitalista do 
que a mão invisível do mercado, muito alardeada por Adam Smith". Destarte, segundo observa Marx (2013, p. 850), o ímpeto por crescente centralização dos capitais levaria ao inevitável colapso da produção e da acumulação no capitalismo, a não ser que forças dispersoras atuem sobre o que foi originalmente concentrado, de modo que as funções internalizadas passem a "funcionar como novos capitais independentes".

Em perspectiva, o moderno padrão multidivisional, tal qual dissecado pela historiografia empresarial de Chandler, possibilitou às grandes corporações a integração vertical dos segmentos e a alocação espacialmente difusa dos capitais como meio de equilíbrio indispensável para a manutenção da acumulação numa escala expansível. Trata-se, nesses termos, de um ajuste organizacional interno que não prescinde ao necessário ajuste espacial das estruturas técnicas para o pleno vigor do movimento de centralização-dispersão geográfica, o que demanda, invariavelmente, a ocorrência de inovações de ordem técnica e operacional.

Dessa forma, é possível que a hierarquia gerencial da grande corporação, que na tese sugerida por Chandler (1977), substituíra os mecanismos de mercado na coordenação das atividades econômicas modernas, seja a força responsável que impede o iminente colapso alardeado por Marx (2013), no que toca à centralização excessiva dos capitais. $\mathrm{O}$ crescente leque de funções internalizado passou a funcionar como capitais independentes, assim como os próprios subespaços de atuação da corporação.

Organizados em rede, tanto os subespaços quanto as subfunções possuem seus próprios registros contábeis que, uma vez drenados para a sede do comando permitem, numa estrutura oligopolista, que a própria competição seja internalizada, aquecendo a concorrência interna por resultados e por equalização dos lucros. Tal arquitetura administrativa remete-se às transformações que buscam atribuir equilíbrio concomitante para interfaces não excludentes do moderno mecanismo da acumulação: a centralização de capitais, rápida sob a forma de fusões; e a inexorável demanda por progressiva descentralização divisional e locacional, organizada sob a disciplina da gestão.

O contraste, segundo Kafkalas (1985), deriva da hierarquia que se institui sobre o espaço, visto o simultâneo movimento de centralização das altas capacidades gestoras e de certos ativos valiosos, à contínua diversificação funcional e geográfica das atividades do objeto em destaque. Rumo a novas latitudes de operação, emerge a máxima expressão dos horizontes espaciais da corporação multilocalizada, reconhecida pelo movimento de transferência desses atores rumo aos mercados estrangeiros, em anuência ao próprio contexto da marcha do capitalismo e à irresistível tendência expansionista que lhe é patente.

No que diz respeito à emergência da corporação multinacional, as contribuições de Hymer (1978) são luminosas. Este autor estende a análise desenvolvida por Chandler (1962) para a escala planetária, indicando a materialização de uma rede de cidades-chave 
associada à gestão territorial das multinacionais, resultado dos níveis de qualificação do trabalho, da renda e do grau de complexidade funcional de cada lugar. Destarte, impõese a configuração de um padrão constantemente variável para as interações espaciais5 entre as diversas cidades que compõem a rede de centros geridos pela corporação, representando, segundo Corrêa (1997), as distintas soluções encontradas por esses atores com vistas à sua própria reprodução.

Daí o reconhecimento de uma dimensão espacial hierárquica como reflexo intrínseco à divisão interna do trabalho típico da corporação multinacional, na qual o centro da gestão das operações das organizações mais pujantes deve estar concentrado em cidades como Nova York, Tóquio, Frankfurt ou São Paulo; "áreas prenhes de ciência, tecnologia e informação, atraindo ações racionais de interesse global", como sugere Santos (2008, p. 42). Os centros urbanos menores ficariam a cargo de operações quotidianas pulverizadas, que demandam menor carga de qualificação profissional e menor simultaneidade das ações, respondendo, assim, a problemas locais específicos.

Cidades em rede, nessa perspectiva, concentram valores de uso (HARVEY, 2005), sob a órbita das demandas orquestradas pela corporação multinacional. Próximo a essa concepção, Corrêa (2014 p. 228) chama atenção para a hierarquia que atribui especialidades funcionais aos centros urbanos, tratando-se "de uma rede necessária ao processo de acumulação de capital, rede que é uma das cristalizações dos diferentes fluxos que se verificam no espaço econômico", gerando diversas complementaridades. Como ressaltam Sposito e Sposito (2017), o empenho para a articulação de múltiplas escalas geográficas por parte de grandes empresas, para além da mera ligação de cidades entre si, contribui para a redefinição dos papéis e da posição dos centros urbanos nas redes às quais pertencem.

Todavia essa capacidade de redefinição constante dos lugares, como adverte Castells (2005) sobre um espaço de fluxos que se institui como processo, não permite atribuir indelével rigidez para as hierarquias reconhecidas por esquemas como o de Chandler-Hymer, no que pertence à arquitetura de lugares em rede confeccionada por grandes empresas. Ante tal realidade, na "lógica espacial do novo sistema, o que importa é a versatilidade de suas redes" (CASTELLS, 2005, p. 476). Indissociável se faz, nessa condição, a emergência do conjunto das redes técnicas e geográficas para satisfazer a urgente demanda por integração própria ao movimento de alargamento do espaço de atuação da corporação multilocalizada, ator que afere funções específicas às técnicas reticulares, assim imbuídas por ordens políticas e econômicas.

5 Para Corrêa (1997), as interações espaciais constituem um amplo e complexo conjunto de deslocamentos de pessoas, mercadorias, capital e informação sobre o espaço geográfico, cujo processo de transformação social faz refletir as diferenças entre os lugares ante a necessidades historicamente identificadas. 
As suas espacialidades encontram cristalização própria nas redes, convertidas em verdadeiros meandros por onde irradia o ordenamento que solidariza e integra diversas localizações ao seu usufruto. Agigantadas em pujança econômica e política, as grandes corporações passam a alimentar relações sinérgicas com o Estado, ator que além de financiar diretamente atividades privadas, exerce notório protagonismo no que diz respeito à implantação, gestão e difusão do aparato reticular por onde fluem as ações capazes de alterar os alicerces das economias regionais.

\section{Corporação e Estado: redes técnicas e sinergias político-econômicas}

A geografia da grande corporação revela-se em função dos objetos fixos erigidos pelo trabalho e animados pelos fluxos promotores de integração territorial, contexto que incita a configuração de um espaço reticular. Como sistemas técnicos indispensáveis ao pleno funcionamento das atividades econômicas, a produção e o ordenamento territorial das redes encontram fundamento no conteúdo político das ações dirigidas pelos atores da sociedade. Espacialmente organizadas de modo reticular, a corporação multilocalizada, ao obter acesso privilegiado às redes técnicas, impõe de modo eficiente as suas práticas de gestão territorial. A estruturação em rede torna-se, como sugere Silva (1997), condição indispensável para a descentralização organizacional e produtiva da corporação, viabilizando interações espaciais em múltiplos circuitos.

Dessa forma, as redes técnicas constituem elementos basilares para a articulação dos diversos processos ligados ao efetivo desempenho das atividades econômicas, integrando a produção, os mercados, as finanças e a informação, como nos lembra Dias (2005). Elas atribuem, segundo Castilho (2016, p. 53), "fluidez e funcionalidade cada vez maiores ao território", e, por isso, convertem-se em indeléveis instrumentos para a realização de práticas sedimentadas pelo poder. $\mathrm{O}$ que remete à própria dimensão espaço-temporal das corporações, cujos mecanismos de difusão e práticas de gestão territorial não prescindem da existência das redes, como decreta Silva (2003).

Nesse sentido, redes representam a soma aferida por uma realidade material significada pelos atores que as frequentam; tanto efetivas, reais e historicamente validadas, quando legitimadas pela ação (SANTOS, 2012), um aparato técnico a postos a responder aos estímulos sociais que lhe são encaminhados. Concretizam, não obstante, o suporte técnico que dá liga ao movimento de centralização dos capitais, evidente na configuração de uma corporação multifuncional, à descentralização progressiva das atividades sobre amplo espaço, que ocorre sob a coordenação da classe gerencial. Em termos objetivos, os alicerces de uma arquitetura organizacional integrada consubstanciam as ações que animam os instrumentos técnicos que equipam o espaço, dando sentido operacional e notório poderio econômico às empresas organizadas de modo reticular. 
Análogo a essa ideia, Santos (2012) propõe um acréscimo aos apontamentos de Taylor e Thrift (1982) acerca do poder dos aspectos organizacionais como parâmetro de controle de mercado exercido por grandes corporações. Assim, "a própria estrutura do espaço constitui uma condição fundamental ao exercício do poder" (SANTOS, 2012, p. 271), indicando o caráter indissociável entre as redes técnicas e o conjunto das ações organizacionais que as animam, uma ordem espacial marcada pela dispersãoconcentração simultâneas no que tange à geografia do objeto em destaque. Ante tal realidade, é possível perceber o ininterrupto processo de reformulação das práticas de ordenamento territorial de uma de uma corporação multilocalizada em busca de vantagens competitivas e do adensamento de suas interações espaciais.

Nessa condição, as atividades difusas mantêm coesão mediante a arquitetura organizacional, que encontra suporte nas redes técnicas para o pleno movimento de integração, garantindo a possibilidade de inúmeras interações intra e extra empresa. Atribuir flexibilidade e eficiência aos mecanismos da lucratividade torna-se a tônica central do processo, demandando o reconhecimento dos encadeamentos econômicos que se efetivam a montante e a jusante. Pautada em uma organização reticular orquestrada por meio de ações e objetos, admite-se a definição de uma corporação em rede como

$$
\begin{aligned}
& \text { um conglomerado multilocalizado e multifuncional } \\
& \text { consubstanciado em múltiplas formas de interações estratégicas } \\
& \text { entre empresas do grupo e fora dele, de modo a possibilitar } \\
& \text { inúmeras configurações espaciais, flexibilização de atividades, de } \\
& \text { recursos e de grupos sociais envolvidos com sua dinâmica (SILVA, } \\
& \text { 2003, p. 30). }
\end{aligned}
$$

Sobremodo, faz-se necessário reconhecer, ante a pujança da grande corporação em articular estruturas espaciais difusas e fluxos de toda ordem, os aspectos relacionados à concentração de conhecimento e aprendizagem em determinadas áreas, com vistas a configurar interdependências profícuas entre diversos atores econômicos que se beneficiam de competências localmente externalizadas. Trata-se do reconhecimento de um arranjo circular que potencializa a aglomeração, consubstanciada por "um conjunto de processos cumulativos, necessariamente envolvendo algum tipo de retorno crescente, por meio do qual a concentração geográfica pode se autorreforçar" (KRUGMAN, 2002, p. $16-17)^{6}$.

$\mathrm{Ou}$, como sugere Santos (2012), os atributos localizados concorrem para uma configuração centrípeta geradora de forças de agregação que funcionam como fatores de convergência, cujos reflexos são expressivos para as dinâmicas regional e urbana. Um

$6 \mathrm{Na}$ opinião desse autor, o reconhecimento de tais sinergias localizadas representa um "renascimento" da geografia econômica, há tempos negligenciada pelos economistas. 
conjunto de estratégias espaciais concentradas que reforçam as prerrogativas de uma lógica circular que não prescinde de crescente integração funcional e territorial, denotando o exercício de estratégias situadas numa escala reduzida de intervenção. A densa integração funcional permite a formação de "cadeias produtivas que envolvem domínio tecnológico e ampla escala comercial sob a racionalidade da empresa", anota Pires do Rio (2012, p. 176), com vistas às organizações reticulares horizontalmente imbricadas como condição precípua para o desenvolvimento de vantagens competitivas amparadas pela cooperação limitada.

As inúmeras interações engendradas sob o exercício das atividades do objeto em tela fazem, nas palavras de Corrêa (1997, p. 313), "originar redes com múltiplos circuitos, refletindo padrões distintos e complexos de localização das diversas unidades da corporação", cuja complementação em diversas escalas espaciais revela a divisão territorial do trabalho agremiada pela gestão. Orientadas por uma organização em rede, as corporações multilocalizadas, mesmo à distância, tornam-se capazes de determinar as modalidades internas de ação de certas regiões.

Em perspectiva, essa trama reticular denota a ocorrência de um ordenamento marcado por horizontalidades e verticalidades (SANTOS, 2012). Pensando-se o lugar como um ponto no espaço marcado pela reunião de feixes de relações e de possibilidades funcionais, as horizontalidades acabam por agrupar o conjunto de situações locais favoráveis à alavancagem vertical de uma corporação. Suscita o estabelecimento de conjunto de ações políticas orientadas, em primeira instância, "para um interesse particular e específico, frequentemente o da atividade hegemônica no lugar", como bem anota Santos (2012, p. 288), de modo que tal ordem localizada possa ser cumpridora de arranjos verticalizados.

Destarte, a grande corporação é portadora de hegemonia e, ao lado do Estado, faz representar a força de primeira instância ante a definição de novas realidades espaciais. Em sinergia, corporações e Estado representam aqueles que com maior pujança exercem influência aos processos decisórios de produção, requalificação e controle de um espaço permeado por fluxos de toda ordem. Não há, na opinião de Santos (2012), uma linha evidente que delimite as práticas desses dois atores no que concerne ao efetivo funcionamento das redes técnicas, de modo que a promoção da fluidez territorial pode ser vista como um empreendimento conjunto entre o público e o privado.

Agigantadas em importância econômica, as corporações passam a negociar com os governos, executando tramas políticas "abertamente, veladamente e inescrupulosamente em interesse próprio", segundo admite Harvey (2013, p. 245). Logo, para além da alocação eficiente focada na máxima produção, atribui-se maior atenção, como aponta Carnoy (1988), para a relação entre quem produz e quem decide a política de desenvolvimento, posto que o problema do incremento das atividades econômicas perpassa pelas arenas da política e da produção. No que concerne à constituição de um espaço reticular, o caráter relacional das ordens políticas e econômicas é registrado por Fisher (2008, p. 61) como uma dupla estruturação simultaneamente verificada, por um 
lado, pelos diversos níveis institucionais administrativos e, por outro, "pelo sistema de fluxos e das redes relacionais das empresas".

De fato, o Estado concentra, em larga escala, a função de provedor dos sistemas técnicos que permitem às corporações multilocalizadas extraírem máximo proveito do espaço. Como anota Harvey (2005), da estrutura estatal é requerido o necessário empenho para a superação das possíveis barreiras que se colocam à fluidez do capital; algo expresso na atuação dessa instituição no que concerne à dotação, no espaço, do conjunto de técnicas reticulares, campo em que o Estado é assaz ativo.

Simétricas às estratégias orquestradas pelo poder, o conluio entre corporações e Estado representa a garantia de resultados geográficos que não teriam ocorrido se tais relações não fossem postas em prática. Indica, para além das já mencionadas capacidades técnicas e organizacionais, a dimensão das teias políticas confeccionadas no contexto da emergência espaço-temporal do objeto em pauta.

Aliás, como sustenta Galbraith (1975, p. 82), as estruturas organizacionais das grandes corporações, se verdadeiramente efetivas, são determinantes para o crescimento de suas prerrogativas econômicas e, em consequência, do seu poder político: "a organização torna-se possível à firma o aumento de tamanho; este é acompanhado pelo aumento de poder sobre os mercados, as atitudes da comunidade e o Estado". O resultado negativo, adverte Markusen (2006), decorre da distorção de lógicas locacionais preestabelecidas pela indução de resultados geográficos determinados por grupos de interesse com base no favor estatal, atribuindo ainda mais força aos grandes conglomerados empresariais, conforme apurado por Penrose (1964), acerca do poderio das gigantes petrolíferas.

Tal como defende Hudson (2006), a plena realização dos imperativos da acumulação requer que as corporações atuem politicamente, assim exercendo patente influência mediante a agenda de implementação das políticas estatais, donde resulta a necessidade do reconhecimento do papel atribuído ao Estado ante uma profícua interpretação das espacialidades de grandes corporações. Nesse sentido, a salvaguarda estatal se dá de modo multiforme, perpassando por uma série de garantias institucionais que versam desde a propriedade ao cumprimento dos contratos firmados, como salienta Harvey (2013). Há, ainda, a dúbia ação do Estado que tanto incentiva e patrocina com recursos públicos os processos de fusão/incorporação quanto impõe limites à centralização excessiva por meio de leis antitruste.

No que é inerente à importância das especificidades históricas e geográficas, cumpre registrar as relações entre Estado e corporações como parte fundamental do conjunto das tramas político-econômicas concretas e factuais, um movimento dialético expresso nas estruturas espaciais submetidas a constante requalificação para o pleno atendimento dos anseios hegemônicos. As correspondências guardam singularidades atinentes às configurações socioespaciais específicas, permeadas pelo maior ou menor envolvimento do arbítrio estatal para a edificação de um arcabouço normativo e técnicoprodutivo a serviço das competências organizacionais das corporações. Em perspectiva, 
a confluência dos poderes econômico e político remete-nos à ideia do controle exercido por determinados atores sobre a amplitude da materialidade socioespacial.

Trata-se, na leitura proposta por Santos e Silveira $(2011,295)$, do cumprimento de ordens técnicas e políticas que confirmam um uso corporativo do território, cujas técnicas e lugares são hierarquizados por "algumas empresas [que] dispõem de maiores possibilidades para a utilização dos mesmos recursos territoriais”, de modo análogo à sugestão de Galbraith (1975). Decretam os autores, nessa perspectiva, que o papel regulador das corporações sobre o conjunto dos objetos constitui premissa objetiva para a empiricização do ordenamento territorial de um país como o Brasil. Tal como sugerem Corrêa (1991) e Silva (1997; 2003), com vistas à dinâmica do território brasileiro, corporações que ordenam múltiplas localizações atribuem funções específicas aos lugares e às redes, apresentando-se como atores fundamentais para a integração nacional.

Assim, a corporação multilocalizada imputa notória influência ao conjunto das políticas públicas destinadas à organização do território, donde derivam laços atados nos bastidores do cenário político. A dinâmica têmporo-espacial de corporações que se organizam em rede pode ser vista como expressão dos esforços para a integração econômica das estruturas produtivas dos países que as sediam, na medida em que a apropriação de determinadas parcelas do espaço pelos atores mais proeminentes da economia representa uma variável-chave para a articulação territorial.

\section{Considerações finais}

A análise dos estudos e recortes de interpretação referentes à dinâmica espacial de corporações multilocalizadas constituiu o objetivo central do presente ensaio. No esforço de tornar inteligíveis as espacialidades do objeto em pauta, privilegiaram-se as leituras que resgatam a consolidação da corporação multidivisional em fricção a pressupostos atinentes à expansão geográfica da acumulação dos capitais em sua acepção crítica. Ademais, elencamos os recortes espaciais referentes a horizontalidades, verticalidades e a noção de rede como subsídios teóricos admissíveis à representação de sua concreta manifestação espacial.

Em realidade, a dinâmica espacial da corporação em rede possui base no movimento sincrônico que a leva a configurar uma série de segmentações técnicas, sociais e territoriais do trabalho hierarquicamente tipificadas. Disso resulta uma sequência de fenômenos espaciais imprescindíveis à própria análise, visto que o movimento de consolidação horizontal e de expansão vertical da corporação multilocalizada faz insurgir subsistemas passíveis de delimitação, cujas múltiplas interações relacionais dão conta de uma composição espaço-temporal de técnicas, normas, atores e ações. A expansão dos horizontes de atuação da corporação multilocalizada se dá por meio de um arranjo espacial explicativo e coerente, um movimento de difusão que configura a existência de uma ordem espacial (GOMES, 2009), permeada por uma geograficidade própria. 
Uma série de interdependências são tecidas no que tange às estruturas locacionais aos níveis da decisão e da criação de especializações produtivas, cuja rede de conexões acaba por atribuir novas funções aos lugares, podendo ainda desqualificá-los. Da implementação desse circuito de relações deriva uma organização espacial fundamentada em níveis hierárquicos que denotam a importância de cada lugar em seus vínculos com a rede do objeto em questão. Destarte, a realidade brasileira constitui-se em rico laboratório para a análise dos caminhos pelos quais grandes corporações edificam as suas complexas espacialidades mediante vínculos mantidos com uma conjuntura superior, sustentada pelas políticas estatais para a integração e ordenamento do território nacional.

\section{Referências}

CARNOY, M. Estado e teoria política. Tradução da equipe de tradutores da PUCCAMP. $2^{\text {a }}$ ed. Campinas: Papirus, 1988. 339p.

CASTELLS, M. A sociedade em rede. Tradução de Roneide Venancio Majer. $8^{\text {a ed. São }}$ Paulo: Paz e Terra, 2005.

CASTILHO, D. Modernização territorial e redes técnicas em Goiás. Goiânia: Editora UFG, 2016. 228p.

CHANDLER, A. D. Strategy and structure. Cambridge: MIT Press, 1962. 463p.

CHANDLER, A. D. The Visible Hand: the managerial revolution in Americam business. Cambridge: Harvard University Press, 1977. 621p.

CHESNAIS, F. A mundialização do capital. São Paulo: Xamã, 1996. 335 p.

COASE, R. H. The Nature of the Firm. Economica, New Series, Vol. 4, nº. 16, Nov., 1937, p. 386-405.

CORRÊA, R. L. Corporação e organização espacial: um estudo de caso. Revista Brasileira de Geografia. Rio de Janeiro, 53, (3), 33-66, jul./set. 1991.

CORRÊA, R. L. Interações espaciais. In: CASTRO, Iná E. de; GOMES, Paulo Cesar da C.; CORRÊA, Roberto L. (Org.). Explorações geográficas: percursos no fim do século. Rio de Janeiro: Bertrand Brasil, 1997. p.279-318.

CORRÊA, R. L. Trajetórias Geográficas. 7 ed. Rio de Janeiro: Bertrand Brasil, 2014.

CLAVAL, P. A diversidade das Geografias Econômicas. GEOgraphia, Vol. 14 n. 27, 2012. p. 7-20.

DIAS, L. Os sentidos da rede: notas para discussão. In: DIAS, Leila C.; SILVEIRA, Rogério L. L. (Org.). Redes, sociedade e territórios. Santa Cruz do Sul: EDUNISC, 2005. 
FISCHER, A. In: FIRKOWSKI, Olga L. C. F.; SPOSITO, Eliseu S. (Org.). Indústria, ordenamento e território: a contribuição de André Fischer. São Paulo: Expressão Popular - UNESP (Programa de Pós Graduação em Geografia), 2008.

FUGITA, M.; KRUGMAN, P.; VENABLES, A. Economia espacial: urbanização, prosperidade econômica e desenvolvimento humano no mundo. Tradução de Bazán Tecnologia Linguística. São Paulo: Futura, 2002.

HARVEY, D. A produção capitalista do espaço. São Paulo: Annablume, 2005. 252p.

HARVEY, D. Os limites do capital. Tradução de Magda Lopes. 1ed. São Paulo: Bointempo, 2013. Recurso eletrônico. 697p.

HYMER, S. Empresas multinacionais: a internacionalização do capital. Rio de Janeiro: Graal, 1978. 118p.

HUDSON, R. Firms as political actors in processes of capital accumulation and regional development. In: TAYLOR, Michael; OINAS, Päivi (Orgs.). Understanding the Firm: spatial and organizational dimensions. Oxford University Press: Oxford - NY. 288p.

KAFKALAS, G. Location of production and forms of spalial integration: theoretical consideralions and some examples from the non-fuel mineral sector. International Journal of Urban and regional Research, 9 (2), p. 233-253. 1985.

LÖSCH, A. Economics of location (1954). Tradução de William H. Woglom com assitência de Wolfgang F. Stolper. New Haven \& London: Yale University Press, 1954. $556 \mathrm{p}$.

MARKUSEN, A. Mudança econômica regional segundo o enfoque centrado no ator. In: DINIZ, Clélio C.; LEMOS, Mauro B. Economia e Território. Belo Horizonte: Editora da UFMG, 2005.

MARKUSEN, A. Distortions in industrial geography: triangulating among industrial firms, financial firms, and the state. In: TAYLOR, Michael; OINAS, Päivi (Orgs.). Understanding the Firm: spatial and organizational dimensions. Oxford University Press: Oxford - NY, 2006. 288p.

MARX, K. Grundrisse: manuscritos econômicos de 1857-1858 - esboços da crítica da economia política. Tradução de Mario Duayer. São Paulo: Bointempo, 2011.

MARX, K. O capital: crítica da economia política. Livro I: o processo de produção do capital. São Paulo: Bointempo, 2013.

MARSHALL, A. Industry and Trade. 3th. Ed. Disponível em: < http://socserv.mcmaster.ca/econ/ugcm/3113/marshall/Industry\&Trade.pdf >. Acesso em Maio de 2017.

MARSHALL, A. Princípios de Economia. Tradução e revisão de Rômulo Almeida e Ottolmy Strauch. Série Os economistas. São Paulo: Editora Nova Cultural Ltda, 1996. 
PENROSE, E. (1959). The Theory of the Growth of the Firm. $4^{\mathrm{a}}$ ed. Oxford: Oxford University Press, 2009.

PENROSE, E. Monopoly and competition in the international petroleum industry. The Yearbook of World Affairs, Vol. 18, London, Stevens. 1964.

PIRES DO RIO, G. Estrutura organizacional e reestruturação produtiva: uma contribuição para a Geografia das corporações. Território. Rio de Janeiro, ano III, n. 5, p. 51-66, jul./dez. 1998.

PIRES DO RIO, G. A espacialidade da economia: superfícies, fluxos e redes. In: CASTRO, Iná E. de; GOMES, Paulo Cesar da C.; CORRÊA, Roberto L. (Org.). Olhares geográficos: modos de ver e viver o espaço. Rio de Janeiro: Bertrand Brasil, 2012. p. 155-187.

SANTOS, M. Técnica, espaço e tempo: globalização e meio técnico-científico informacional. 5ed. São Paulo: EDUSP, 2008. 174p.

SANTOS, M. A natureza do espaço: técnica e tempo, razão e emoção. 4 ed. São Paulo: EDUSP, 2012.

SANTOS, M; SILVEIRA, M. L. O Brasil: território e sociedade no início do século XXI. 15 Ed. Rio de Janeiro: Record, 2011. 475 p.

SILVA, C. A. F. da. Dinâmica espacial do capital bancário - difusão, integração e crise: estudo de caso do Banco Nacional S.A. 1997. 204 f. Tese (Doutorado em Geografia) - Programa de Pós Graduação em Geografia, Universidade Federal do Rio de Janeiro. 1997.

SILVA, C. A. F. da. Grupo André Maggi: corporação e rede em áreas de fronteira. Cuiabá: Entrelinhas, 2003. 222p.

SMITH, A. A Riqueza das Nações: investigação sobre sua natureza e suas causas. Vol. 1. Tradução de Luiz João Baraúna. São Paulo: Editora Nova Cultura Ltda. 1996.

SPOSITO, M. E. B.; SPOSITO, E. S. Articulação entre múltiplas escalas geográficas: lógicas e estratégias espaciais de empresas. Geousp - Espaço e Tempo (Online), v. 21, n. 2, p. 462-479, agosto. 2017.

TAYLOR, M. J.; TRIRIFT, N. J. Industrial linkage and the segmented economy: some theortical proposals. In: Environment and planning, v. 14, p. 1601-1613, 1982.

WEBER, A. Theory of the location of industries. In: FRIEDRICH, Carl J. (Ed.). Alfred Weber's theory of the location of industries. Chicago (EUA), The University of Chicago Press, 1929. 306 p.

WILLAMSON, O. Markets and hierarchies: some elementar considerations. The American Economic Review, v. 63, n.2, p. 316-25, maio de 1973. 
WILLAMSON, O. The modern Corporation: origins, evolution, atributes. Journal of Economic Literature, v. 19, n.4, p. 1.537-68, dez. 1981.

\section{Fernando Fernandes de Oliveira}

Graduado e mestre em Geografia pela Universidade Federal de Uberlândia. Atualmente cursa doutorado no Programa de Pós-Graduação em Geografia do Instituto de Estudos Socioambientais da Universidade Federal de Goiás. É professor efetivo do Instituto Federal Goiano - Campus Avançado Ipameri.

Av. Vereador José Benevenuto, Qd. 11, s/n Ipameri - GO. CEP: 75.780-000.

E-mail: fernando.oliveira@ifgoiano.edu.br

Recebido para publicação em novembro de 2017 Aprovado para publicação em fevereiro de 2018 